\title{
The role of sodium bicarbonate in the nucleation of noctilucent clouds
}

\author{
J. M. C. Plane \\ School of Environmental Sciences, University of East Anglia, Norwich NR4 7TJ, United Kingdom
}

Received: 30 September 1999 / Revised: 4 February 2000 / Accepted: 7 February 2000

\begin{abstract}
It is proposed that a component of meteoric smoke, sodium bicarbonate $\left(\mathrm{NaHCO}_{3}\right)$, provides particularly effective condensation nuclei for noctilucent clouds. This assertion is based on three conditions being met. The first is that $\mathrm{NaHCO}_{3}$ is present at sufficient concentration $\left(\approx 10^{4} \mathrm{~cm}^{-3}\right)$ in the upper mesosphere between 80 and $90 \mathrm{~km}$. It is demonstrated that there is strong evidence for this based on recent laboratory measurements coupled with atmospheric modelling. The second condition is that the thermodynamics of $\mathrm{NaHCO}_{3}\left(\mathrm{H}_{2} \mathrm{O}\right)_{n}$ cluster formation allow spontaneous nucleation to occur under mesospheric conditions at temperatures below $140 \mathrm{~K}$. The Gibbs free energy changes for forming clusters with $n=1$ and 2 were computed from quantum calculations using hybrid density functional/Hartree-Fock (B3LYP) theory and a large basis set with added polarization and diffuse functions. The results were then extrapolated to higher $n$ using an established dependence of the free energy on cluster size and the free energy for the sublimation of $\mathrm{H}_{2} \mathrm{O}$ to bulk ice. A 1-dimensional model of sodium chemistry was then employed to show that spontaneous nucleation to form ice particles $(n>100)$ should occur between 84 and $89 \mathrm{~km}$ in the high-latitude summer mesosphere. The third condition is that other metallic components of meteoric smoke are less effective condensation nuclei, so that the total number of potential nuclei is small relative to the amount of available $\mathrm{H}_{2} \mathrm{O}$. Quantum calculations indicate that this is probably the case for major constituents such as $\mathrm{Fe}(\mathrm{OH})_{2}, \mathrm{FeO}_{3}$ and $\mathrm{MgCO}_{3}$.
\end{abstract}

Key words: Atmospheric composition and structure (aerosols and particles; cloud physics and chemistry; middle atmosphere - composition and chemistry)

\section{Introduction}

Noctilucent clouds (NLC) occur at high latitudes in the summer mesosphere, when the temperature falls below 150 K (e.g. Seele and Hartogh, 1999; Lübken, 1999). Water vapour, which is present at mixing ratios of only a few parts per million above $80 \mathrm{~km}$, is then able to condense on available nuclei to form particles that can grow to more than $20 \mathrm{~nm}$ in radius, when they can be observed by lidar (e.g. von Cossart et al., 1999) and also become optically visible (Thomas, 1991). Meteor ablation has been proposed as a major source of condensation nuclei, and two distinct types of nuclei have been considered. First are clusters of $\mathrm{H}_{2} \mathrm{O}$ around metallic ions such as $\mathrm{Fe}^{+}, \mathrm{Mg}^{+}$and $\mathrm{Na}^{+}$, which then undergo successive hydration with falling temperature (Witt, 1969). A difficulty with this nucleation source has recently emerged from kinetic studies of the mechanisms which neutralize metallic ions in the upper mesosphere (Cox and Plane, 1998; Rollason and Plane, 1998; Plane et al., 1999b). These studies have shown that metallic ions should be rapidly neutralized below $95 \mathrm{~km}$ by forming molecular ions which undergo dissociative recombination with electrons. Indeed, the predicted depletion of metallic ions below $95 \mathrm{~km}$ has been confirmed by rocket-borne mass spectrometry (e.g., Kopp, 1997). Hence, it is unlikely that metallic ions are a major source of condensation nuclei. On the other hand, proton hydrates of the form $\mathrm{H}^{+}\left(\mathrm{H}_{2} \mathrm{O}\right)_{n}$ sometimes occur at sufficiently high concentrations below $90 \mathrm{~km}$ to play a role in NLC formation (Balsiger et al., 1996). However, Reid (1990) has shown that the observed electron "bite-outs" in NLC layers are not consistent with an ion nucleation mechanism.

The second type of condensation nucleus that has been proposed is meteoric "smoke" particles (Hunten et al., 1980). Although this term conjures up the image of particles being produced directly in the trail of an ablating meteoroid, this is rarely the case because the median mass of incoming meteoroids is only about $10 \mu \mathrm{g}$ 
(Hunten et al., 1980). When such small particles ablate, the resulting concentration of metal atoms, ions and oxides is too low for coagulation to compete with the outward diffusion of the meteor trail (Rosinski and Snow, 1961). Hence, a typical trail loses its identity completely, diffusing into the background atmosphere before any significant coagulation occurs. Recognizing this fact, Hunten et al. (1980) assumed that the lower limit to the smoke particle size is a molecular radius of $2 \AA$. These workers constructed a meteoric dust model which included a fairly detailed treatment of ablation, particle coagulation and sedimentation. This model showed that most ablation occurred between 80 and $90 \mathrm{~km}$, and that coagulation did not significantly reduce the concentration of the smallest particles until below $80 \mathrm{~km}$. Although more recent work (e.g. Taylor, 1995) indicates that the average meteoroid velocity of $14.5 \mathrm{~km} \mathrm{~s}^{-1}$ assumed by Hunten et al. (1980) was too low by about a factor of 2 (and hence the peak ablation altitude is actually around $95 \mathrm{~km}$ ), this should not greatly affect the conclusions of the earlier study. The implication is that if smoke particles do provide condensation nuclei for NLC at the summer mesopause around $88 \mathrm{~km}$, then these particles are either individual molecules or small macromolecules less than $10 \AA$ in radius.

The purpose of the present work is to begin to explore the nature of these smoke particles. Here the case will be made for sodium bicarbonate $\left(\mathrm{NaHCO}_{3}\right)$ being an important nucleating agent. To establish this, the following questions need to be addressed. First, is $\mathrm{NaHCO}_{3}$ present in the upper mesosphere in sufficient concentrations? Second, do the thermodynamics for $\mathrm{NaHCO}_{3}$ clustering with $\mathrm{H}_{2} \mathrm{O}$ allow spontaneous nucleation to occur within the ranges of humidity and temperature that characterize the high-latitude summer mesopause? Third, what about other metallic species formed from meteoric ablation, are there in fact too many nucleating agents available, thus preventing particles growing to the optically visible range that give rise to NLC? These questions will now be considered in turn.

Before doing so, the author would like to acknowledge the significant contribution that Professor Lance Thomas has made in three areas relevant to this paper. First, Professor Thomas played an important role in the early development of the sodium resonance fluorescence lidar (Gibson et al., 1979) while working at the Rutherford Appleton Laboratory. Later at the University of Wales at Aberystwyth, his group developed a model of the mesospheric Na layer that showed for the first time that the characteristic features of the layer could be explained by the gas-phase chemistry of sodium alone (Thomas et al., 1983). Most recently, his group have been active in studying the phenomenon of mesospheric summer echoes, which are closely related to NLC (Thomas et al., 1996).

\section{$\mathrm{NaHCO}_{3}$ in the mesosphere}

The only sodium species that can be observed directly in the upper atmosphere are atomic $\mathrm{Na}$, measured by lidar since the advent of the tunable dye laser (e.g. Gibson et al., 1979; Plane et al., 1998, 1999a), and $\mathrm{Na}^{+}$ions, detected by rocket-borne mass spectrometry (e.g. Kopp, 1997). Thus the molecular forms of sodium have to be inferred from chemical/transport models (e.g. Thomas et al., 1983; Plane, 1991; McNeil et al., 1995; Plane et al., 1998, 1999a, b). Figure 1 is a schematic drawing of the important chemistry that sodium is known to undergo in the upper mesosphere. Apart from the reactions enclosed by the dashed line (which are the subject of the present study), all of these reactions have been studied as isolated processes in the laboratory, and most of their rate coefficients have been measured at temperatures around $200 \mathrm{~K}$ (e.g. Ager and Howard, 1987; Plane and Helmer, 1994; Plane et al., 1999a, b). This applies in particular to the sequence of reactions that convert atomic $\mathrm{Na}$ to $\mathrm{NaHCO}_{3}$ via $\mathrm{NaO}$ and $\mathrm{NaOH}$.

Rajasekhar and Plane (1993) demonstrated using $\mathrm{ab}$ initio quantum theory that $\mathrm{NaHCO}_{3}$ should be a relatively stable molecule in the mesosphere, since its only exothermic reaction is with atomic $\mathrm{H}$. Plane et al. (1999b) have recently confirmed experimentally that this reaction does occur very slowly at low temperatures, as required by sodium models: if there were not a path for breaking down $\mathrm{NaHCO}_{3}$ to $\mathrm{Na}$, the atomic $\mathrm{Na}$ layer could not be sustained below $95 \mathrm{~km}$.

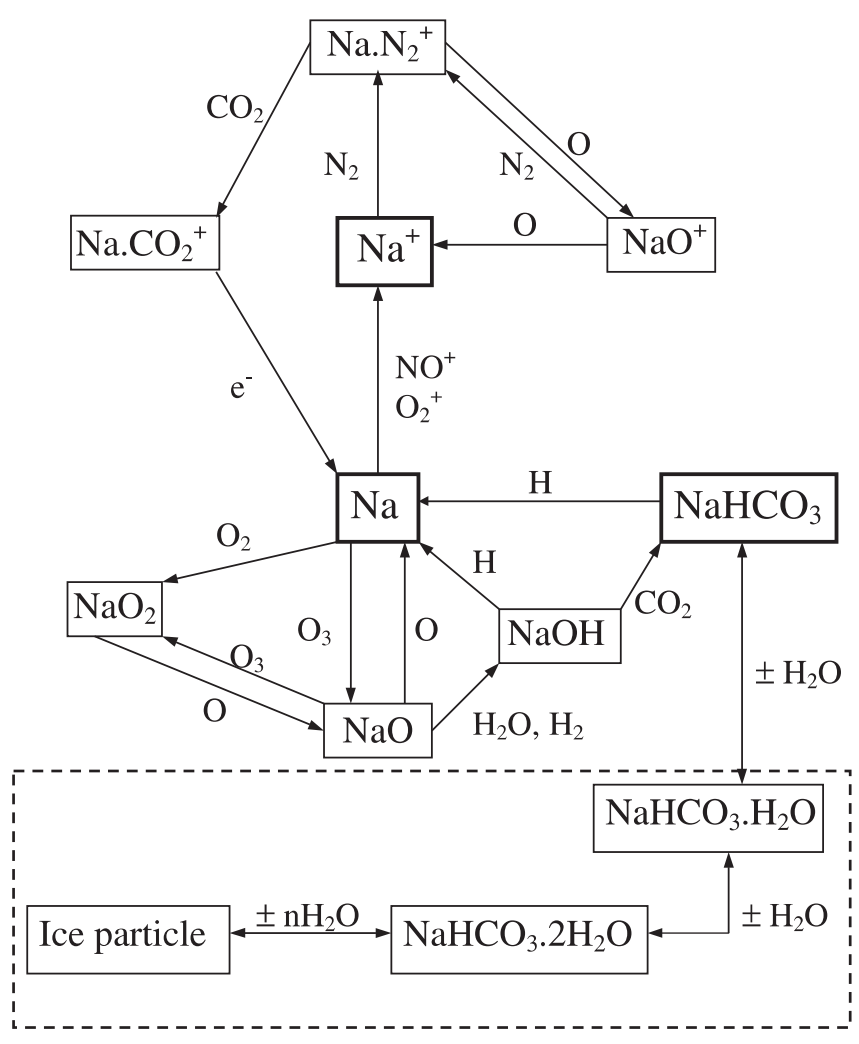

Fig. 1. Schematic drawing of the important chemistry of sodium in the upper mesosphere $\left(\mathrm{NaO}_{3}\right.$ and $\mathrm{NaCO}_{3}$ are not included for the sake of clarity). The major sodium species are in the thick-edged boxes. The cluster reactions between $\mathrm{NaHCO}_{3}$ and $\mathrm{H}_{2} \mathrm{O}$, that are proposed to occur at the cold summer mesopause, are surrounded by the dashed line 
The Mean Annual Na Layer at $40^{\circ} \mathrm{N}$

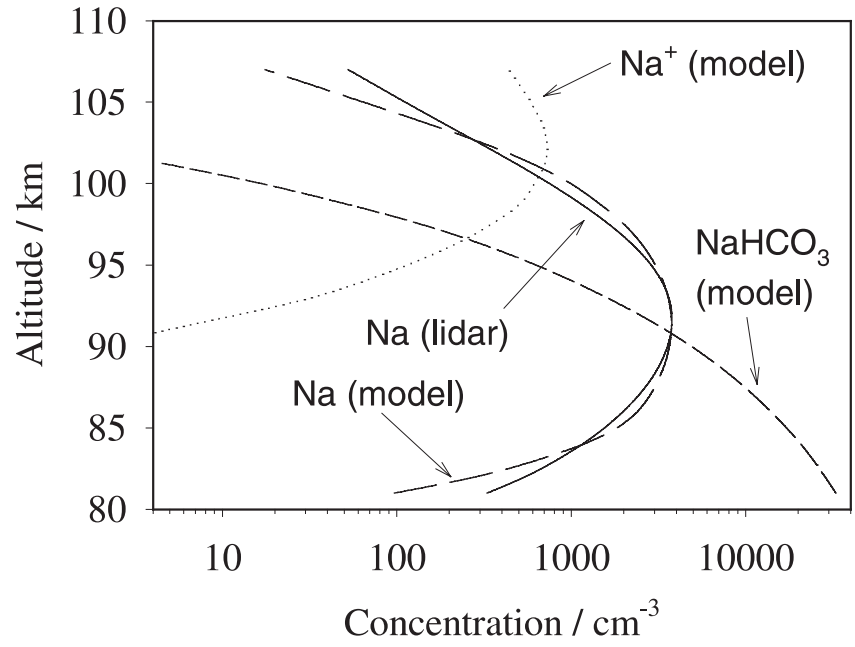

Fig. 2. Annual mean profiles of $\mathrm{Na}, \mathrm{Na}^{+}$and $\mathrm{NaHCO}_{3}$ predicted by the UEA $1 \mathrm{D}$ sodium model at $40^{\circ} \mathrm{N}$. The modelled $\mathrm{Na}$ layer is compared with the average from a 3-year set of lidar observations (Plane et al., 1999a)

Figure 2 illustrates the annual average profiles of the major sodium species between 80 and $110 \mathrm{~km}$, predicted by the UEA sodium model (Plane et al., 1999a) for midlatitude conditions at $40^{\circ} \mathrm{N}$ (this will be contrasted later with the cold summer mesopause at high latitudes). The $\mathrm{Na}$ layer peaks at about $90 \mathrm{~km}$, in good agreement with a very large data base of lidar observations (Plane et al., 1999a). $\mathrm{Na}^{+}$is the dominant species in the lower thermosphere, and $\mathrm{NaHCO}_{3}$ in the upper mesosphere. Note that the predicted $\mathrm{NaHCO}_{3}$ concentration at $85 \mathrm{~km}$ is about $10^{4} \mathrm{~cm}^{-3}$, an order of magnitude larger than the concentration of meteoric smoke particles that appears to be required to nucleate a visible NLC with an ice particle concentration of about $100 \mathrm{~cm}^{-3}$ (Jensen and Thomas, 1991). This sodium model has now been shown to reproduce in detail the observed seasonal and latitudinal variations of the $\mathrm{Na}$ layer (Plane et al., 1998, 1999a). It therefore seems reasonable to conclude that $\mathrm{NaHCO}_{3}$ is the major sodium reservoir immediately below the $\mathrm{Na}$ layer peak at $90 \mathrm{~km}$, and that its concentration should be sufficient to provide a significant source of condensation nuclei.

\section{Thermodynamics of $\mathrm{NaHCO}_{3}$-water clusters}

Although solid $\mathrm{NaHCO}_{3}$ is quite hygroscopic and is highly soluble in bulk water, there appears to be no information concerning the thermodynamics of clusters formed between isolated $\mathrm{NaHCO}_{3}$ and $\mathrm{H}_{2} \mathrm{O}$ molecules in the gas phase. This deficiency was addressed here by carrying out high-level quantum theory calculations using hybrid density functional/Hartree-Fock (B3LYP) theory, within the GAUSSIAN 98 set of programmes (Frisch et al., 1998). The large, flexible 6-311+G(2d,p) basis set was employed, which has both polarization and diffuse functions added to the atoms. This combination of theory and basis set was chosen because theoretical estimates of the thermochemistries for a wide variety of reactions compare well with experimental measurements (see later) (Foresman and Frisch, 1996). The geometries of $\mathrm{NaHCO}_{3}, \mathrm{NaHCO}_{3} \cdot \mathrm{H}_{2} \mathrm{O}$ and $\mathrm{NaHCO}_{3} \cdot 2 \mathrm{H}_{2} \mathrm{O}$ were first optimized at the B3LYP/6-311+G(2d,p) level. The vibrational frequencies of each species were then calculated, since these are required both to make zeropoint-energy corrections to the cluster binding energies, and to compute the binding entropies.

Calculations on clusters containing more than two $\mathrm{H}_{2} \mathrm{O}$ were not attempted because at this level of theory these become very expensive in computer resources. In order to benchmark the theory, calculations were also carried out on $\mathrm{NaOH}, \mathrm{H}_{2} \mathrm{O}$ and $\mathrm{CO}_{2}$, for which there is experimental data on their respective geometries, dipole moments and vibrational frequencies. As shown in Table 1, there is in general excellent agreement. The greatest discrepancies are in the vibrational frequencies of $\mathrm{NaOH}$; however, the experimental frequencies were determined in a matrix isolation study, and the frequencies of the isolated molecule could be significantly shifted compared to the matrix environment.

The optimised geometries of $\mathrm{NaHCO}_{3}$ and the first and second $\mathrm{H}_{2} \mathrm{O}$ clusters are illustrated in Fig. 3, and their molecular parameters are listed in Table 2. There are several points to note. First, $\mathrm{NaHCO}_{3}$ is highly ionized with a large dipole moment of nearly 7 Debye, so that the clustering reaction with $\mathrm{H}_{2} \mathrm{O}$ will be enhanced by a strong dipole-dipole interaction. Second, the two $\mathrm{H}_{2} \mathrm{O}$ molecules are bound directly to the $\mathrm{Na}$ atom, which has a Mulliken charge of +0.65 , and the binding is further stabilized by hydrogen bonds with the bicarbonate anion (shown as broken lines in Fig. 3). Third, even after the addition of two $\mathrm{H}_{2} \mathrm{O}$ molecules, the cluster still has a large dipole moment which should facilitate its further growth. A final point is that the assumption of Hunten et al. (1980) that the initial smoke particles above $80 \mathrm{~km}$ would have a radius of $2 \AA$ is not a bad approximation to the spherically-averaged dimensions of $\mathrm{NaHCO}_{3}$.

The computed binding energies of the clusters are then:

$$
\begin{aligned}
& \mathrm{NaHCO}_{3}+\mathrm{H}_{2} \mathrm{O} \rightarrow \mathrm{NaHCO}_{3} \cdot \mathrm{H}_{2} \mathrm{O} \\
& \Delta H_{0}^{\circ}=-69.8 \mathrm{~kJ} \mathrm{~mol}^{-1} \\
& \mathrm{NaHCO}_{3} \cdot \mathrm{H}_{2} \mathrm{O}+\mathrm{H}_{2} \mathrm{O} \rightarrow \mathrm{NaHCO}_{3} \cdot 2 \mathrm{H}_{2} \mathrm{O} \\
& \Delta H_{0}^{\circ}=-55.2 \mathrm{~kJ} \mathrm{~mol}^{-1}
\end{aligned}
$$

The uncertainty in these energies is probably around $\pm 12 \mathrm{~kJ} \mathrm{~mol}^{-1}(95 \%$ confidence level) at this level of theory, based on a comparison of experimental and theoretical thermochemistries for a wide range of molecules (Foresman and Frisch, 1996). These binding energies are quite large, and are a significant fraction of the first and second binding energies of $\mathrm{H}_{2} \mathrm{O}$ to bare $\mathrm{Na}^{+}$ions $\left(\Delta H_{298}^{\circ}=-100.3\right.$ and $-82.8 \mathrm{~kJ} \mathrm{~mol}^{-1}$, respectively (Džidić and Kebarle, 1970)).

These theoretical results can also be used to estimate the enthalpy changes for the reaction of atomic $\mathrm{H}$ with 
Table 1. Calculated molecular parameters at the B3LYP/6-311+ G(2d,p) level of theory for $\mathrm{NaOH}_{2} \mathrm{H}_{2} \mathrm{O}$ and $\mathrm{CO}_{2}$. For comparison, experimental values are shown in parenthesis

\begin{tabular}{lllll}
\hline Species & Geometry $^{\mathrm{a}}$ & $\begin{array}{l}\text { Dipole } \\
\text { moment }^{\mathrm{b}}\end{array}$ & Rotational constants $^{\mathrm{c}}$ & Vibrational frequencies $^{\mathrm{d}}$ \\
\hline $\mathrm{NaOH}$ & $r_{\mathrm{Na}-\mathrm{O}}=1.95\left(1.95^{\mathrm{e}}\right)$ & $6.58\left(6.83^{\mathrm{f}}\right)$ & $12.61\left(12.57^{\mathrm{f}}\right)$ & $214\left(337^{\mathrm{g}}\right)(\mathrm{x} 2), 565\left(431^{\mathrm{g}}, 437^{\mathrm{h}}\right)$, \\
& $r_{\mathrm{O}-\mathrm{H}}=0.95$, linear & & & $3966\left(\approx 3600^{\mathrm{g}}\right)$ \\
$\mathrm{H}_{2} \mathrm{O}$ & $r_{\mathrm{O}-\mathrm{H}}=0.96\left(0.96^{\mathrm{i}}\right)$ & $2.08\left(1.85^{\mathrm{j}}\right)$ & $826\left(842^{\mathrm{i}}\right), 428\left(438^{\mathrm{i}}\right)$, & $1618\left(1594^{\mathrm{i}}\right), 3812\left(3651^{\mathrm{i}}\right)$, \\
& $L_{\mathrm{H}-\mathrm{O}-\mathrm{H}}=105.2\left(104.5^{\mathrm{i}}\right)$ & & $282\left(280^{\mathrm{i}}\right)$ & $3917\left(3756^{\mathrm{i}}\right)$ \\
$\mathrm{CO}_{2}$ & $\begin{array}{l}r_{\mathrm{C}-\mathrm{O}}=1.16\left(1.16^{\mathrm{i}}\right), \\
\text { linear }\end{array}$ & 0.0 & $11.73\left(11.75^{\mathrm{i}}\right)$ & $677\left(667^{\mathrm{i}}\right)(\mathrm{x} 2), 1363\left(1385^{\mathrm{i}}\right)$, \\
& & & & $2400\left(2349^{\mathrm{i}}\right)$ \\
\hline
\end{tabular}

a Bond length in $\AA$, bond angle in degrees

${ }^{b}$ In Debye $\left(=3.336 \times 10^{-30} \mathrm{~cm}\right)$

c In $\mathrm{GHz}$

${ }^{\mathrm{d}} \mathrm{In} \mathrm{cm}^{-1}$

${ }^{\text {e }}$ Kuijpers et al. (1976)
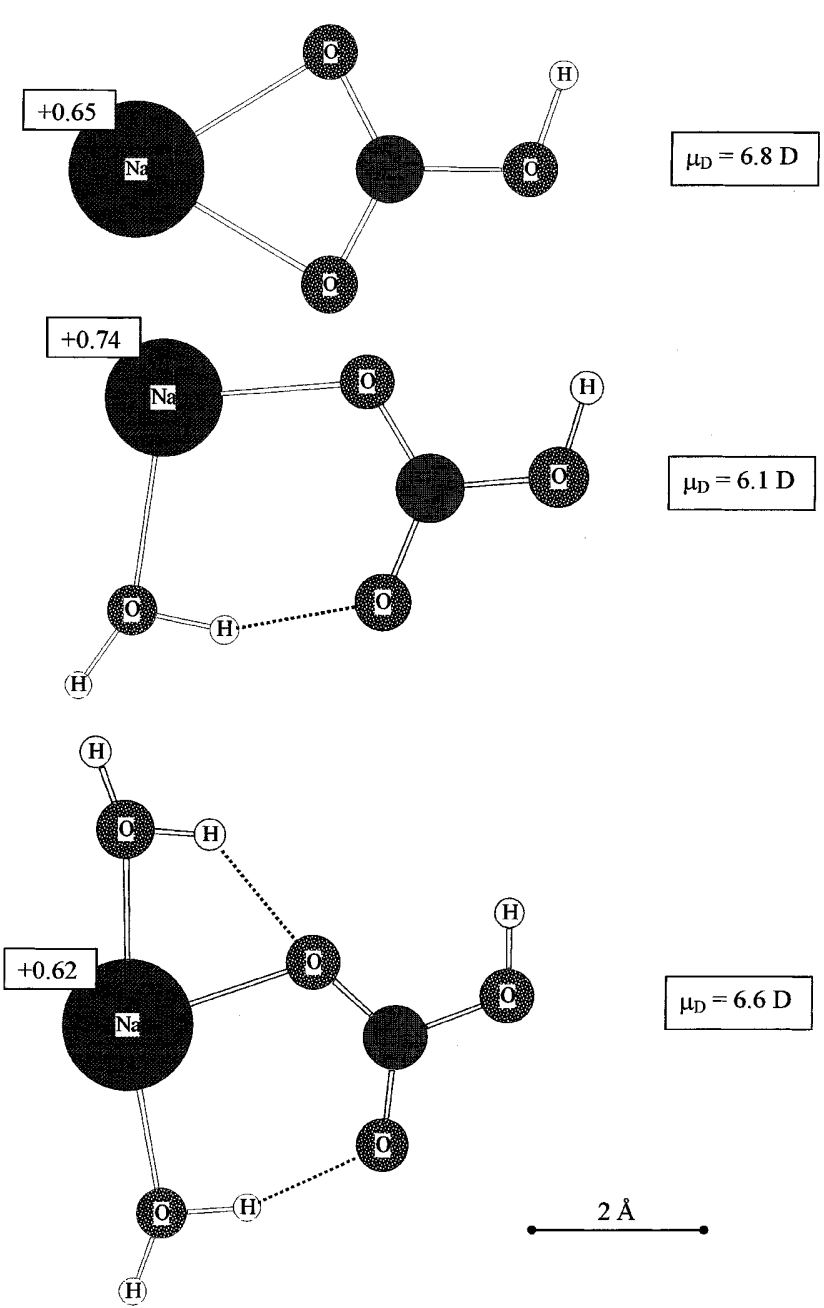

Fig. 3. Geometries and dipole moments $\left(\mu_{\mathrm{D}}\right)$ of $\mathrm{NaHCO}_{3}$ and the first and second $\mathrm{H}_{2} \mathrm{O}$ clusters, calculated at the B3LYP/6$311+\mathrm{G}(2 \mathrm{~d}, \mathrm{p})$ level of theory. All structures are planar. The dark shaded atomic centre is carbon

$\mathrm{NaHCO}_{3}$ and the $\mathrm{H}_{2} \mathrm{O}$ clusters (note that the reactions of $\mathrm{NaHCO}_{3}$ with other radical species such as $\mathrm{OH}$ and $\mathrm{O}$ are quite endothermic and will not occur in the mesosphere (Rajasekhar and Plane, 1993)):
${ }^{\mathrm{f}}$ Kawashima et al. (1996)

${ }^{g}$ Acquista and Abramowitz (1969)

${ }^{\mathrm{h}}$ Spinar and Margrave (1958)

${ }^{\mathrm{i}}$ Chase et al. (1985)

${ }^{\mathrm{j}}$ Lide (1998)

$$
\begin{aligned}
& \mathrm{NaHCO}_{3}+\mathrm{H} \rightarrow \mathrm{Na}+\mathrm{H}_{2} \mathrm{O}+\mathrm{CO}_{2} \\
& \Delta H_{0}^{\circ}=-59.2 \mathrm{~kJ} \mathrm{~mol}^{-1} \\
& \mathrm{NaHCO}_{3} \cdot \mathrm{H}_{2} \mathrm{O}+\mathrm{H} \rightarrow \mathrm{Na}+2 \mathrm{H}_{2} \mathrm{O}+\mathrm{CO}_{2} \\
& \Delta H_{0}^{\circ}=+10.6 \mathrm{~kJ} \mathrm{~mol}^{-1} \\
& \mathrm{NaHCO}_{3} \cdot 2 \mathrm{H}_{2} \mathrm{O}+\mathrm{H} \rightarrow \mathrm{Na}+3 \mathrm{H}_{2} \mathrm{O}+\mathrm{CO}_{2} \\
& \Delta H_{0}^{\circ}=+65.8 \mathrm{~kJ} \mathrm{~mol}^{-1}
\end{aligned}
$$

These results demonstrate that $\mathrm{NaHCO}_{3} \cdot 2 \mathrm{H}_{2} \mathrm{O}$ (and the higher clusters) should not undergo chemical reaction in the mesosphere (other than the addition or loss of $\mathrm{H}_{2} \mathrm{O}$ ), and this may also apply to the first $\mathrm{H}_{2} \mathrm{O}$ cluster. That is, once these clusters start to form, their stability will only be governed by the temperature and to a lesser extent the mixing ratio of $\mathrm{H}_{2} \mathrm{O}$.

The equilibrium constants $K_{1}$ and $K_{2}$ can now be calculated by statistical mechanics using the data in Table 2. Inspection of this table shows that both the first and second $\mathrm{H}_{2} \mathrm{O}$ clusters have several vibrational modes with frequencies below $100 \mathrm{~cm}^{-1}$. These modes really correspond to hindered internal rotations of the $\mathrm{H}_{2} \mathrm{O}$ molecules against the $\mathrm{NaHCO}_{3}$. However, treating them in the limit as free rotors (Benson, 1968) rather than harmonic oscillators produced very little difference in the calculated values of $K_{1}$ and $K_{2}$ over the temperature range of $130-220 \mathrm{~K}$. Hence, the rotational and vibrational partition functions were calculated assuming that the clusters are rigid rotors and that all vibrations are harmonic. This yields:

$$
\begin{aligned}
& K_{1}(T)=2.22 \times 10^{-26} \exp (7590 / T) \mathrm{cm}^{3} \text { molecule }^{-1} \\
& K_{2}(T)=3.81 \times 10^{-26} \exp (5890 / T) \mathrm{cm}^{3} \text { molecule }^{-1}
\end{aligned}
$$

The equilibrium constants $K_{n}$ for $n \geq 3$ can now be estimated by analogy with the hydration thermodynamics of metallic ions, where the Gibbs free energy for addition of the $n$th $\mathrm{H}_{2} \mathrm{O}, \Delta G_{n-1, n}$, is proportional to $\log n$ up to about $n=10$ (Džidić and Kebarle, 1970). This is illustrated for the present case in Fig. 4, which is a plot of $\Delta G_{n-1, n}$ versus $n$ at a temperature of $135 \mathrm{~K}$. At higher $n, \Delta G_{n-1, n}$ becomes more negative again and tends in the limit to the free energy of sublimation for $\mathrm{H}_{2} \mathrm{O}$ on bulk 
Table 2. Calculated molecular parameters at the $\mathrm{B} 3 \mathrm{LYP} / 6-311+\mathrm{G}(2 \mathrm{~d}, \mathrm{p})$ level of theory for $\mathrm{NaHCO}_{3}, \mathrm{NaHCO}_{3} \cdot \mathrm{H}_{2} \mathrm{O}$ and $\mathrm{NaHCO}_{3} \cdot 2 \mathrm{H}_{2} \mathrm{O}$. The geometries and dipole moments are contained in Fig. 3

\begin{tabular}{llc}
\hline Species & $\begin{array}{l}\text { Rotational } \\
\text { constants }^{\mathrm{a}}\end{array}$ & Vibrational frequencies $^{\mathrm{b}}$ \\
\hline $\mathrm{NaHCO}_{3}$ & $12.29,3.34,2.63$ & $112,247,333,570,581,700,833,1008,1237,1389,1659,3802$ \\
$\mathrm{NaHCO}_{3} \cdot \mathrm{H}_{2} \mathrm{O}$ & $5.53,1.95,1.44$ & $67,85,86,132,263,320,332,571,610,636,702,829,976,1010,1246,1381,1659$, \\
& & $1707,2802,3804,3917$ \\
$\mathrm{NaHCO}_{3} \cdot 2 \mathrm{H}_{2} \mathrm{O}$ & $2.33,1.57,0.94$ & $30,69,79,83,98,130,153,207,250,288,351,487,533,582,603,620,696,825,947$, \\
& & $1015,1237,1377,1617,1673,1717,2915,3618,3815,3913,3915$ \\
\hline
\end{tabular}

${ }^{\mathrm{a}} \mathrm{In} \mathrm{GHz}$

${ }^{\mathrm{b}} \mathrm{In} \mathrm{cm}^{-1}$

Gibbs free energy change for sequential addition of $\mathrm{H}_{2} \mathrm{O}$ to $\mathrm{NaHCO}_{3}$ at $135 \mathrm{~K}$

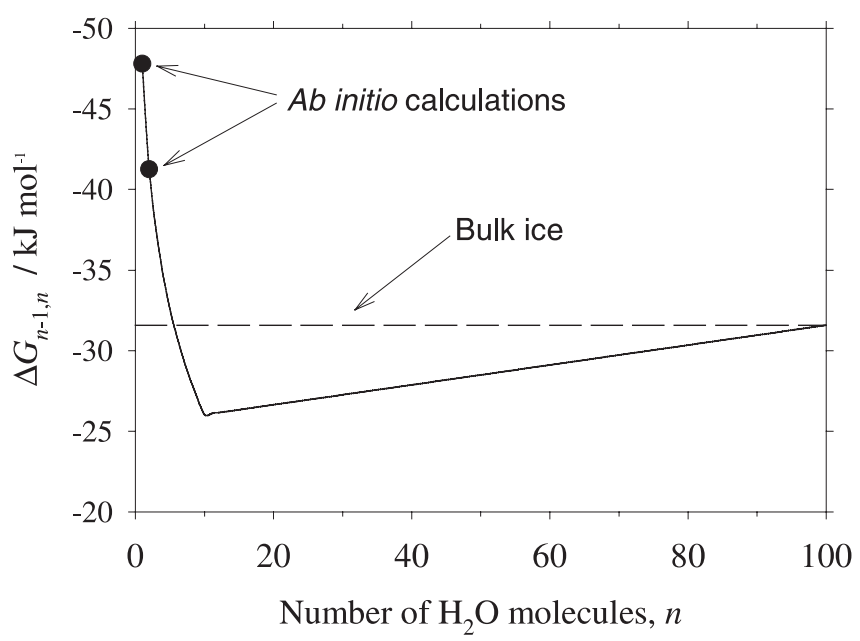

Fig. 4. Hypothetical dependence of $\Delta G_{n-1, n}$, the Gibbs free energy for the addition of the $n$th $\mathrm{H}_{2} \mathrm{O}$ to a $\mathrm{NaHCO}_{3}\left(\mathrm{H}_{2} \mathrm{O}\right)_{n-1}$ cluster, as a function of $n$ at $135 \mathrm{~K} . \Delta G_{0,1}$ and $\Delta G_{1,2}$ are derived from the present $\mathrm{ab}$ initio quantum calculations. The value for bulk ice is extrapolated from the measurements of Marti and Mauersberger (1993)

ice (Marti and Mauersberger, 1993). In Fig. 4 this is assumed arbitrarily to occur at $n=100$.

A free energy dependence of this form has the following important property. The addition of $\mathrm{H}_{2} \mathrm{O}$ becomes increasingly less favourable up to $n=10$ (in this case). However, if the temperature is low enough (or $\left[\mathrm{H}_{2} \mathrm{O}\right]$ high enough) to reach this point, then the subsequent addition of $\mathrm{H}_{2} \mathrm{O}$ becomes more and more favourable, causing spontaneous growth and the formation of ice particles. This is illustrated in Fig. 5, which shows the relative equilibrium concentrations of $\mathrm{NaHCO}_{3}$, the first three $\mathrm{H}_{2} \mathrm{O}$ clusters, and "ice particles" (defined as $n>100$ ), plotted as a function of temperature from 120 to $220 \mathrm{~K}$. The $\mathrm{H}_{2} \mathrm{O}$ mixing ratio is fixed at $3 \mathrm{ppm}$, typical of the high-latitude summer mesopause (Seele and Hartogh, 1999). $\mathrm{NaHCO}_{3}$ is the dominant form above $190 \mathrm{~K}$; at lower temperatures, successively higher $\mathrm{H}_{2} \mathrm{O}$ clusters dominate the equilibrium population, until spontaneous growth occurs at about $137 \mathrm{~K}$. Note that the temperature at which this runaway nucleation occurs is sensitive to the turning point in
$\mathrm{NaHCO}_{3}-\mathrm{H}_{2} \mathrm{O}$ cluster formation

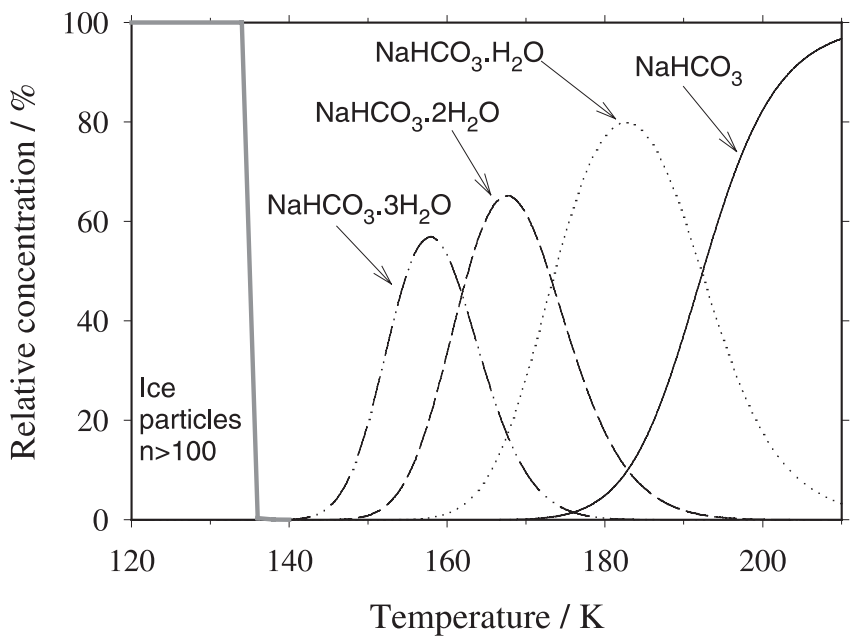

Fig. 5. Equilibrium populations of $\mathrm{NaHCO}_{3}$ and a selection of $\mathrm{NaHCO}_{3}\left(\mathrm{H}_{2} \mathrm{O}\right)_{n}$ clusters $(n=1,2,3$ and $>100)$, as a function of temperature. The $\mathrm{H}_{2} \mathrm{O}$ mixing ratio is constant at $3 \mathrm{ppm}$

the plot of $\Delta G_{n-1, n}$ versus $n$ (Fig. 4). The value of $n=10$ was chosen here for illustrative purposes because there is a large body of evidence that the temperature in the $85-90 \mathrm{~km}$ height range must fall below $140 \mathrm{~K}$ for NLC to form [e.g., Seele and Hartogh, 1999].

To explore the likely cluster populations in the high latitude summer mesosphere, the thermodynamics of these cluster reactions were incorporated into the UEA 1-dimensional sodium model by making the following approximations. First, it was assumed that only the first cluster, $\mathrm{NaHCO}_{3} \cdot \mathrm{H}_{2} \mathrm{O}$, is able to react with $\mathrm{H}$, with a rate coefficient arbitrarily set to that of $\mathrm{NaHCO}_{3}+\mathrm{H}$ [Plane et al., 1999a]. Second, because the rate of addition and loss of $\mathrm{H}_{2} \mathrm{O}$ from the clusters is likely to be much faster than the rate of formation of $\mathrm{NaHCO}_{3}$ from $\mathrm{Na}$ or the reverse, the clusters were assumed to be in a quasi-equilibrium with $\mathrm{NaHCO}_{3}$.

The model was then run for conditions of $70^{\circ} \mathrm{N}$ in July [Plane et al., 1998]. A new temperature profile obtained from falling sphere measurements at Andoya $\left(69^{\circ} \mathrm{N}\right)$ [Lübken, 1999] was used, where the mesopause was found to occur at $88 \mathrm{~km}$ with a temperature of $129 \mathrm{~K}$. Note that the use of a climatological temperature profile is appropriate here, since the aim of this study is 
Major Sodium Species, July $70^{\circ} \mathrm{N}$

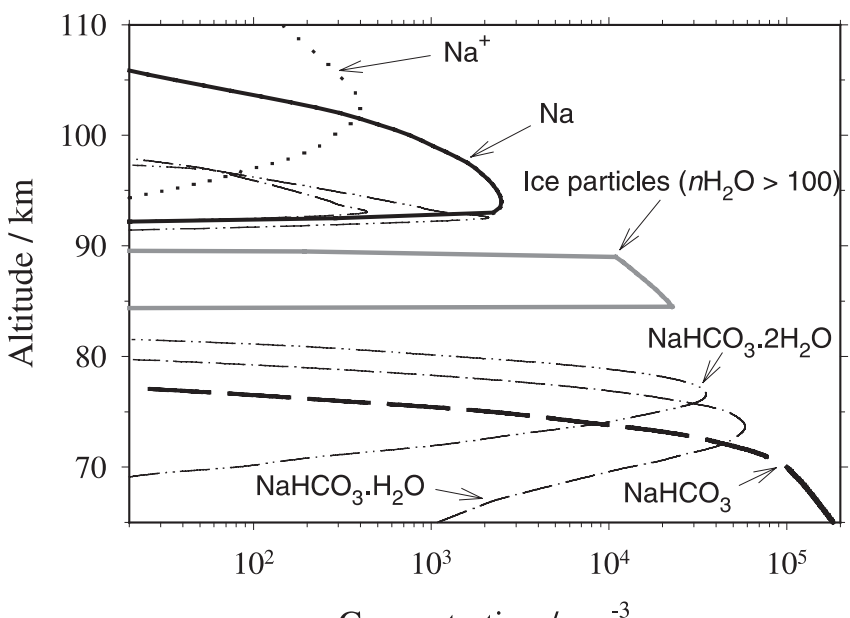

Fig. 6. Profiles of $\mathrm{Na}, \mathrm{Na}^{+}, \mathrm{NaHCO}_{3}$, and $\mathrm{NaHCO}_{3}\left(\mathrm{H}_{2} \mathrm{O}\right)_{n}$ clusters $(n=1,2$ and $>100)$, predicted by the 1D sodium model for early July at $70^{\circ} \mathrm{N}$

to establish whether the free energy of $\mathrm{NaHCO}_{3}$-water cluster formation is of the right order to allow particle growth under summer mesopause conditions. Future studies could address the role of short-term cooling induced by gravity waves in triggering nucleation.

The modelled profiles of $\mathrm{Na}, \mathrm{Na}^{+}, \mathrm{NaHCO}_{3}$ and the clusters are illustrated in Figure 6. The peak of the $\mathrm{Na}$ layer is now at $92.5 \mathrm{~km}$, in accord with lidar observations at several high latitude stations [Gardner et al., 1988; Kurzawa and von Zahn, 1990; Plane et al., 1998]. Note that this is significantly higher than at midlatitudes (cf. Figure 2). Another contrast with the midlatitude case is that $\mathrm{NaHCO}_{3}$ only occurs as a free molecule below $80 \mathrm{~km}$ (although it will eventually polymerise with itself and other metallic compounds, a process that is not included in the present model). Above $80 \mathrm{~km} \mathrm{NaHCO}$ is clustered with $\mathrm{H}_{2} \mathrm{O}$, and runaway nucleation is predicted to occur in a layer between 84 and $89 \mathrm{~km}$. Models of NLC (e.g. Jensen and Thomas, 1991) require nucleation at this height, followed by sedimentation of the growing ice particles to around $83 \mathrm{~km}$, where visible NLC are observed. Finally, the very steep underside of the Na layer, and the gap of 2$3 \mathrm{~km}$ between the $\mathrm{Na}$ and NLC layers (Fig. 6), are in excellent agreement with the lidar observations of Hansen et al. (1989).

\section{Presence of other metallic species}

The most abundant metals in meteoroids are $\mathrm{Fe}$ and $\mathrm{Mg}$ (Plane, 1991). Fe appears to ablate quite efficiently, giving rise to an observable atomic Fe layer peaking at about $85 \mathrm{~km}$ (Helmer et al., 1998). Recent laboratory studies (Plane et al., 1999b) have shown that the two likely stable reservoirs of iron above $80 \mathrm{~km}$ are $\mathrm{FeO}_{3}$, which forms most rapidly, and $\mathrm{Fe}(\mathrm{OH})_{2}$, which is the most stable thermodynamically. Figure 7 illustrates the
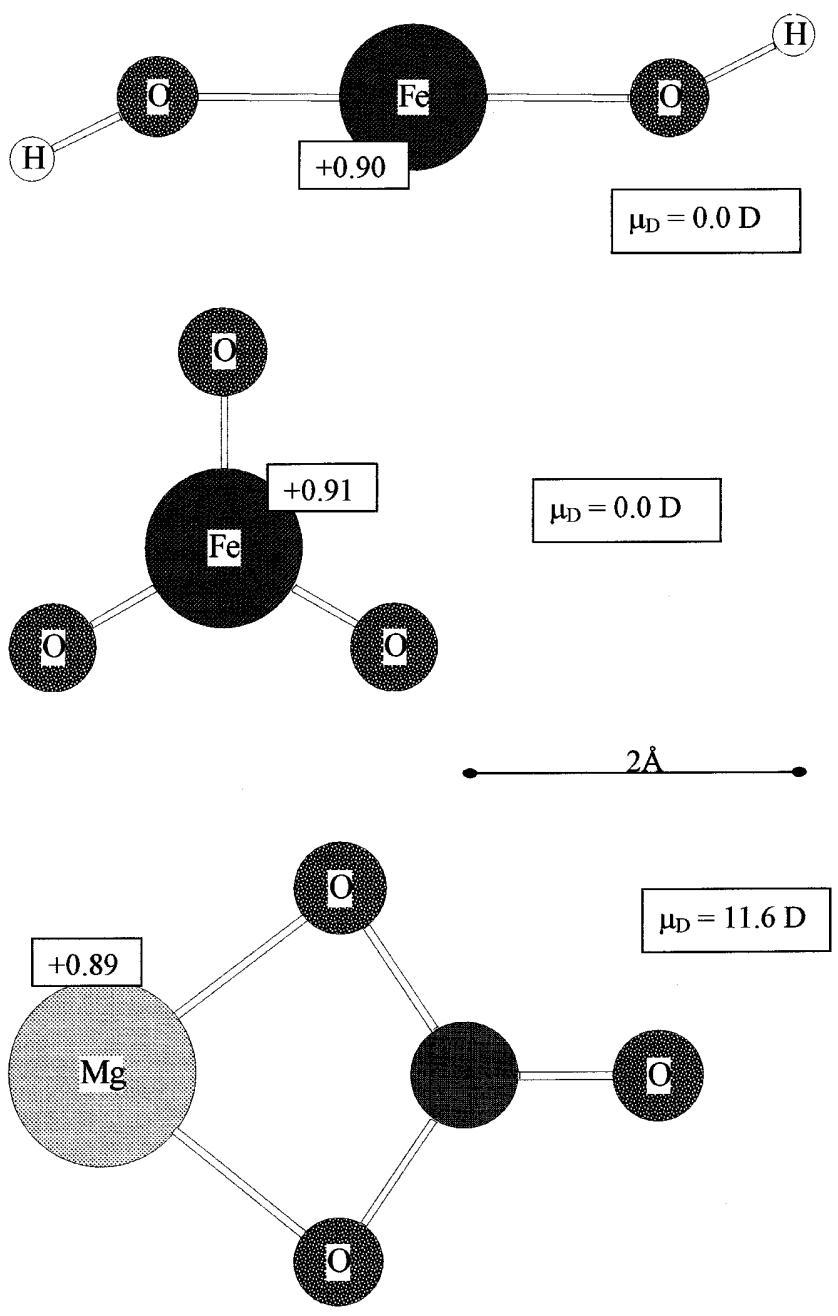

Fig. 7. Geometries and dipole moments $\left(\mu_{\mathrm{D}}\right)$ of $\mathrm{Fe}(\mathrm{OH})_{2}, \mathrm{FeO}_{3}$ and $\mathrm{MgCO}_{3}$, calculated at the B3LYP/6-311+ G(2d,p) level of theory. All structures are planar. The dark shaded atomic centre is carbon

calculated geometries of these species at the B3LYP/ $6-311+G(2 d, p)$ level of theory. These molecules have zero dipole moments, so that they are unlikely to bind strongly to $\mathrm{H}_{2} \mathrm{O}$ and act as effective condensation nuclei.

In the case of $\mathrm{Mg}$, recent laboratory studies by $\mathrm{R}$. J. Rollason and the author have shown that $\mathrm{MgCO}_{3}$ will form readily above $80 \mathrm{~km}$ from the recombination of $\mathrm{MgO}$ and $\mathrm{CO}_{2}$. The calculated geometry of this species is also illustrated in Fig. 7. Note that the molecule has a huge dipole moment of 11.6 Debye, which should make it an excellent condensation nucleus. However, when a water molecule actually approaches $\mathrm{MgCO}_{3}$, further quantum calculations (at the B3LYP/6-311+G(2d,p) level) reveal that the electrostatic forces are large enough to effect a chemical reaction, producing $\mathrm{Mg}(\mathrm{OH})_{2}$ and $\mathrm{CO}_{2}$. The dihydroxide has the same linear structure as $\mathrm{Fe}(\mathrm{OH})_{2}$ (Fig. 7), with a zero dipole moment, and is therefore a less effective nucleus. In any case, the absence of an observed layer of atomic $\mathrm{Mg}$ in the mesosphere implies that this metal does not ablate efficiently from meteoroids (Plane and Helmer, 1995), as is also the case for Ca (McNeil et al., 1998). 


\section{Conclusions}

This study has attempted to show that there is a prima facie case for $\mathrm{NaHCO}_{3}$, a component of meteoric smoke, being a particularly effective condensation nucleus for NLC. This assertion is based on the following points: that there is strong evidence for the presence of $\mathrm{NaHCO}_{3}$ at sufficient concentrations in the upper mesosphere; that the thermodynamics for $\mathrm{NaHCO}_{3}\left(\mathrm{H}_{2} \mathrm{O}\right)_{n}$ cluster formation allow spontaneous nucleation to occur under mesospheric conditions at temperatures below $140 \mathrm{~K}$; and that other metallic compounds are probably less effective condensation nuclei, so that the total number of potential nuclei is small relative to the amount of available $\mathrm{H}_{2} \mathrm{O}$.

The most speculative aspect of the present study is the extrapolation of the Gibbs free energy change to clusters with more than two $\mathrm{H}_{2} \mathrm{O}$ molecules (Fig. 4). Unfortunately, laboratory studies of the neutral $\mathrm{H}_{2} \mathrm{O}$ clusters of metallic compounds such as $\mathrm{NaHCO}_{3}$ will be extremely challenging because of the difficulty of detecting the clusters without working at such high concentrations that in situ polymerization starts to dominate. Conversely, ab initio calculations on closedshell species such as $\mathrm{NaHCO}_{3}$ and $\mathrm{H}_{2} \mathrm{O}$ appear to be a very promising approach for future studies.

Acknowledgements. This work was supported by grant GR3/11754 from the Natural Environment Research Council of the UK. The author acknowledges with pleasure the encouragement of Prof. L. Thomas in the mid-1980s to enter the field of mesospheric sodium chemistry.

Topical Editor D. Murtagh thanks G. Witt and E. Murad for their help in evaluating this paper.

\section{References}

Acquista, N., and S. Abramowitz, Structure of the alkali hydroxides. V. The infrared spectra of matrix-isolated RbOH, RbOD, $\mathrm{NaOH}$, and NaOD, J. Chem. Phys., 51, 2911, 1969.

Ager, J. W., and C. J. Howard, Rate coefficient for the gas phase reaction of $\mathrm{NaOH}$ with $\mathrm{CO}_{2}, J$. Geophys. Res., 92, 6675-6678, 1987.

Balsiger, F., E. Kopp, M. Friedrich, K. M. Torkar, U. Wälchli, and G. Witt, Geophys. Res. Lett., 23, 93-96, 1996.

Benson, S. W., Thermochemical kinetics, John Wiley and Sons, New York, 1968.

Chase, M. W., C. A. Davies, J. R. Downey, D. J. Frurip, R. A. McDonald, and A. N. Syverud, JANAF Thermochemical Tables, 3rd Edn, J. Phys. Chem. Ref. Data, 14, 1985.

Cox, R. M., and J. M. C. Plane, An ion-molecule mechanism for the formation of neutral sporadic Na layers, J. Geophys. Res., 103, 6349-6360, 1998.

Džidić, I., and P. Kebarle, J. Phys. Chem., 74, 1466-1474, 1970.

Foresman, J. B., and A. Frisch, Exploring chemistry with electronic structure methods, Gaussian, Pittsburgh PA, 1996.

Frisch, M. J., G. W. Trucks, H. B. Schlegel, G. E. Scuseria, M. A. Robb, J. R. Cheeseman, V. G. Zakrzewski, J. A. Montgomery, Jr., R. E. Stratmann, J. C. Burant, S. Dapprich, J. M. Millam, A. D. Daniels, K. N. Kudin, M. C. Strain, O. Farkas, J. Tomasi, V. Barone, M. Cossi, R. Cammi, B. Mennucci, C. Pomelli, C. Adamo, S. Clifford, J. Ochterski, G. A. Petersson, P. Y. Ayala, Q. Cui, K. Morokuma, D. K. Malick, A. D. Rabuck, K. Raghavachari, J. B. Foresman, J. Cioslowski, J. V. Ortiz, B. B. Stefanov, G. Liu, A. Liashenko, P. Piskorz, I. Komaromi,
R. Gomperts, R. L. Martin, D. J. Fox, T. Keith, M. A. Al-Laham, C. Y. Peng, A. Nanayakkara, C. Gonzalez, M. Challacombe, P. M. W. Gill, B. Johnson, W. Chen, M. W. Wong, J. L. Andres, C. Gonzalez, M. Head-Gordon, E. S. Replogle, and J. A. Pople, Gaussian 98 Revision A.6, Gaussian, Pittsburgh PA, 1998.

Gardner, C. S., D. C. Senft, and K. H. Kwon, Lidar observations of substantial sodium depletion in the summertime Arctic mesosphere, Nature, 332, 142-144, 1988.

Gibson, A., L. Thomas, and S. Bhattachacharyya, Lidar observations of the ground-state hyperfine structure of sodium and of temperature in the upper atmosphere, Nature, 281, 131-132, 1979.

Hansen, G., M. Serwazi, and U. von Zahn, First detection of a noctilucent cloud by lidar, Geophys. Res. Lett., 16, 1445-1448, 1989.

Helmer, M., J. M. C. Plane, J. Qian, and C. S. Gardner, A model of meteoric iron in the upper atmosphere, J. Geophys. Res., 103, $10913,1998$.

Hunten, D. M., R. P. Turco, and O. B. Toon, Smoke and dust particles of meteoric origin in the mesosphere and stratosphere, J. Atmos. Sci., 37, 1342, 1980.

Jensen, E. J., and G. E. Thomas, Charging of mesospheric particles: implications for electron density and particle coagulation, J. Geophys. Res., 96, 18 603-18 615, 1991.

Kawashima, Y., R. D. Suenram, and E. Hirota, Determination of nuclear quadrupole coupling constants of $\mathrm{NaOH}, \mathrm{KOH}$, $\mathrm{RbOH}$, and $\mathrm{CsOH}$ and electric dipole moment of $\mathrm{NaOH}$, J. Molec. Spectr., 175, 99-103, 1996.

Kopp, E., On the abundance of metal ions in the lower ionosphere, J. Geophys. Res., 102, 9667-9674, 1997.

Kuijpers, P., T. Torring, and A. Dymanus, Vibration-rotation interaction in the microwave spectrum of $\mathrm{NaOH}$. Chem. Phys., 15, 457-461, 1976.

Kurzawa, H., and U. von Zahn, Sodium density and atmospheric temperature in the mesopause region in polar summer, J. Atmos. Terr. Phys., 52, 981-993, 1990.

Lide, D. R., Handbook of physics and chemistry, 78th Edn.; CRC Press, Boca Raton, FL, 1998.

Lübken, F.-J., Thermal structure of the Arctic summer mesosphere, J. Geophys. Res., 104, 9135-9149, 1999.

Marti, J., and K. Mauersberger, A survey and new measurements of ice vapor pressure at temperatures between 170 and $250 \mathrm{~K}$, Geophys. Res. Lett., 20, 363-366, 1993.

McNeil, W. J., E. Murad, and S. T. Lai, Comprehensive model for the atmospheric sodium layer, J. Geophys. Res., 100, 16847 , 1995.

McNeil, W. J., S. T. Lai, and E. Murad, Differential ablation of cosmic dust and implications for the relative abundances of atmospheric metals, J. Geophys. Res., 103, 10 899-10 911, 1998.

Plane, J. M. C., The chemistry of meteoric metals in the Earth's upper atmosphere, Int. Rev. Phys. Chem., 10, 55, 1991.

Plane, J. M. C., and M. Helmer, Laboratory studies of the chemistry of meteoric metals, in Research in chemical kinetics, vol 2, Eds. R. G. Compton and G. Hancock, Elsevier, Amsterdam, 1994.

Plane, J. M. C., and M. Helmer, Laboratory study of the reactions $\mathrm{Mg}+\mathrm{O}_{3}$ and $\mathrm{MgO}+\mathrm{O}_{3}$ : implications for the chemistry of magnesium in the upper atmosphere, Faraday Disc., 100, 411430, 1996.

Plane, J. M. C., R. M. Cox, J. Qian, M. Pfenninger, G. C. Papen, C. S. Gardner, and P. J. Espy, The mesospheric Na layer at extreme high latitudes in summer, J. Geophys. Res., 103, 6381, 1998a.

Plane, J. M. C., C. S. Gardner, J. Yu, C. Y. She, R. R. Garcia, and H. C. Pumphrey, The Mesospheric Na layer at $40^{\circ} \mathrm{N}$ : modelling and observations, J. Geophys. Res., 104, 3773-3788, 1999a.

Plane, J. M. C., R. M. Cox, and R. J. Rollason, Metallic layers in the mesopause and lower thermosphere region, Adv. Space Res., 24, 1559-1570, 1999b.

Rajasekhar, B., and J. M. C. Plane, An ab initio study of dissociative electron attachment to $\mathrm{NaHCO}_{3}$ and $\mathrm{NaCO}_{3}$, and 
the role of these reactions in the formation of sudden sodium layers, Geophys. Res. Lett., 20, 21, 1993.

Reid, G. C., Ice particles and electron "bite-outs" at the summer polar mesopause, J. Geophys. Res., 95, 13 891-13 896, 1990.

Rollason, R. J., and J. M. C. Plane, A kinetic study of the reactions between $\mathrm{Fe}^{+}$ions and $\mathrm{O}_{3}, \mathrm{O}_{2}$ and $\mathrm{N}_{2}, J$. Chem. Soc., Faraday Trans., 94, 3067-3075, 1998.

Rosinski, J., and R. H. Snow, Secondary particulate matter from meteor vapors, J. Meteorol., 18, 736-745, 1961.

Seele, C., and P. Hartogh, Water vapor of the polar middle atmosphere: annual variation and summer mesosphere conditions as observed by ground-based microwave spectroscopy, Geophys. Res. Lett., 26, 1517-1520, 1999.

Spinar, L. H., and J. L. Margrave, Absorption spectra of gaseous alkali metal hydroxides at high temperatures, Spectrochim. Acta, 12, 244, 1958.
Taylor, A. D., The Harvard radio meteor project meteor velocity distribution reappraised, Icarus, 116, 154-158.

Thomas, G. E., Mesospheric clouds and the physics of the mesopause region, Rev. Geophys., 29, 553-575, 1991.

Thomas, L., M. C. Isherwood, and M. R. Bowman, A theoretical study of the height distribution of sodium in the mesosphere, J. Atmos. Terr. Phys., 45, 587-594, 1983.

Thomas, L., K. P. Marsh, D. P. Wareing, I. Astin, and H. Chandra, VHF echoes from the midlatitude mesosphere and the thermal structure observed by lidar, J. Geophys. Res., 101, 12 867-12 877, 1996.

von Cossart, G., J. Fiedler, and U. von Zahn, Size distributions of NLC particles as determined from 3-color observations of NLC by ground-based lidar, Geophys. Res. Lett., 26, 1513-1516, 1999.

Witt, G., The nature of noctilucent clouds, Space Res., 9, 157-169, 1969. 